\title{
Os pilares da educação Guarani Kaiowá: Kunumi há Chamiri - a criança Kaiowá
}

\section{The pillars of Guarani Kaiowá education: Kunumi há Chamiri - Kaiowá child}

\section{Pilares de educación Guarani Kaiowá: Kunumi há Chamiri - el niño Kaiowá}

\author{
Claudemiro Pereira Lescano ${ }^{1}$ \\ Heitor Queiroz de Medeiros ${ }^{2}$
}

DOI: http://dx.doi.org/10.20435/serie-estudos.v20i52.1382

\begin{abstract}
Resumo: A pesquisa aborda os vastos saberes indígenas que formam os pilares da educação Kaiowá, descrevendo o caminho da educação das crianças como menino (Kunumi) e menina (Chamiri). Apresenta dados sobre o espaço e os valores da escola, o caminhar da escola na busca de ser educação escolar indígena na comunidade e no sistema escolar, bem como aponta orientações para a educação escolar indígena. A pesquisa foi desenvolvida através de observação, visitas e conversas com os sábios, rezadores e crianças Kaiowá. Percebeu-se que, em consideração aos jovens e à geração atual, o retorno para casa será por meio de leitura e da escrita, e a escola é ferramenta especial para criar o novo caminho de retorno, em que haverá o fortalecimento da identidade e a compreensão da interculturalidade. É necessário que, hoje, a escola seja compreendida na sua dimensão e complexidade por professores, lideranças, jovens e pela própria comunidade, porque só será educação escolar indígena quando existir uma clareza do significado em relação à escola para a comunidade. Com isso, abre-se uma porta, um novo caminho de retorno da comunidade para casa, para o entendimento da sua identidade, para valorização de seus saberes e também para se ter a noção e a abertura no sentido de compreender que já não estamos sós, que existem outras sociedades, as quais devem ser compreendidas e respeitadas, assim como devemos ser respeitados por elas.
\end{abstract}

Palavras-chave: saberes tradicionais; educação Kaiowá; criança Kaiowá.

Abstract: The research approaches the broad indigenous knowledges that constitute the pillars of Kaiowá education, describing the path of children education as a boy (Kunumi) and girl (Chamiri). It presents data about school space and values, the trajectory of seeking to build an indigenous scholar education at the community and the school system, as well as pointing out orientations for indigenous scholar education. The research was developed through the observation, visits and

\footnotetext{
${ }^{1}$ Universidade Federal da Grande Dourados (UFGD), Dourados, Mato Grosso do Sul, Brasil.

${ }^{2}$ Universidade Católica Dom Bosco (UCDB), Campo Grande, Mato Grosso do Sul, Brasil.
} 
conversations with the wise people, givers of blessings and Kaiowá children. It was possible to realize that, for young and actual generation, home return will be through the reading and writing, and school is an especial tool in order to create a new returning, based on the strengthening of identity and the understanding of interculturality. It's necessary, today, that school can be understood on its dimension and complexion by teachers, leaders, youth and Community, because it will only be indigenous education when exists a clearness of the relation of the school for the Community. Thus, it has been opened a door, with a new return path of community to home, for the understanding of their identity, for the valorization of the knowledge and, also, in order to achieve the notion and openness in the sense that we are not alone anymore and that there are other societies, which must be understood and respected as well as we must be respected by them.

Keywords: traditional knowledge; Kaiowá education; Kaiowá children.

Resumen: La investigación aborda el vasto conocimiento indígena que forma los pilares de la educación Kaiowá, describiendo el camino de la educación de los niños como chicos (Kunumi) y chicas (Chamiri). Presenta datos sobre el espacio y los valores de la escuela, el camino de la escuela en la búsqueda de ser la educación escolar indígena en la comunidad y en el sistema escolar, así como señala las pautas para la educación escolar indígena. La investigación se desarrolló a través de la observación, visitas y conversaciones con los sabios, rezadores y niños Kaiowá. Se dio cuenta de que, en consideración a los jóvenes y la generación actual, el regreso a casa será a través de la lectura y la escritura, y la escuela es una herramienta especial para crear el nuevo camino de retorno, que fortalecerá la identidad y la comprensión de interculturalidad. Es necesario que hoy en día la escuela sea entendida en su tamaño y complejidad por maestros, líderes, jóvenes y la propia comunidad, porque será una educación escolar indígena solo cuando haya una claridad de significado en relación a la escuela para la comunidad. Esto abre una puerta, una nueva forma para que la comunidad regrese a casa, comprenda su identidad, valore sus conocimientos y también tenga la noción y la apertura para comprender que ya no estamos solos, que hay otras sociedades, que deben ser entendidas y respetadas, así como debemos ser respetados por ellas.

Palabras clave: conocimiento tradicional; educación Kaiowá; niño Kaiowá.

\section{INTRODUÇÃO}

Este artigo é parte dos resultados da pesquisa realizada na aldeia indígena Taquaperi, que é uma das oito reservas demarcadas pelo governo federal de 1915 até 1929. Os moradores desta aldeia são maioria Pa'i Tavyterã ou Kaiowá, que viveram em terras tradicionais das regiões de $\tilde{N} u$ Po'i-Paranhos, Cerro PerõCoronel Sapucaia, Guassuty-Aral Moreira, e Ita Poty-Amambai.

O Tavyterã, conhecido como Kaiowá, é o povo da floresta ka'aguygua ou ka'aguy pegua, sendo que Kaiowá é nome que veio dos não índios. Os Kaiowá têm caminho de rezas: o ñe'ẽngary, feito diretamente ao Ňande Ramõi Papa, considerado o ancestral. As rezas são respondidas por meio de trovões, relâmpagos, chuvas e tempestades, mas sem neblina, que o próprio Ňande Jára (nosso Deus) envia. 
Segundo Brasil (2016), com dados da Secretaria Especial de Saúde Indígena (SESAI), a aldeia Taquaperi abrange uma população aproximada de 3.270 pessoas, em uma reserva de 1.977 hectares, distribuídas em quatro regiões: Cerro, Taquara, Mangai e Taquaperi.

Os Kaiowá se espelham no seu ancestral- Ñane Rembypy-, que também chamam de Ñane Ramõi, o criador de todas as coisas, como: terra-yvy, águas-y, animais-mymba, aves-guyra, plantas-temity ypy. E a criação dele ainda continua se estendendo no vasto e intenso mundo, segundo a cosmovisão do Kaiowá. Por isso os cantos e as rezas são as práticas mais importantes para o povo.

O chefe da família sempre foi o mais velho, o sábio Omba'e Kuaáva, e só na ausência do ancião (Ñamoi) a Jari (anciã) assume a responsabilidade. Quando o Ñamoi morre, o mais velho da família é indicado como Terekua, aquele que tem obrigação de cuidar e ser líder da família.

A organização social atual das comunidades indígenas Kaiowá é resultado de longo processo de contato, de resistência, de negociação e de nova organização social.

Os Kaiowá constituem seus saberes por meio de diversos valores internos e externos, ou seja, adquirem materiais ou tecnologias externas, mas o uso destes materiais ainda é fortemente baseado na espiritualidade e na coletividade.

A língua Guarani é a própria lei que expressa os pensamentos, entendimentos, valores, regras e significados, é por meio dela que se canalizam todos os conhecimentos do povo. Assim, para transmitir a sabedoria e se diferenciar de outros povos, não há possibilidade de mudar, pois sua mudança altera as regras, os valores e os sentidos da rede de sabedoria construída, como rezas, danças, cantos, mitos e ética, que formam as leis.

A continuidade da língua Guarani é a continuidade da lei do povo, nas diversas gerações, e por meio deste canal ocorre a transmissão de saberes, como: história, saberes do tempo, do espaço e dos diversos donos ou Jára. As crianças têm que continuar ouvindo esses saberes por meio da oralidade; são histórias ou ensinamentos que servem de exemplo moral para a juventude, como inspiração de vida.

Os ensinamentos têm momentos para serem transmitidos, eles são usados na ocasião propícia e precisam ser usados gradualmente. As histórias, os cantos, as rezas e a ética só podem ser usados na hora em que a pessoa precisa. 
É assim que se norteia o ensinamento das crianças. Não se pode ensinar os elementos culturais quando não são necessários, principalmente para as crianças que não necessitam.

A educação vem recheada de significados, como remédios tradicionais, benzimentos, determinados tipos de cantos e rezas, a forma de construir as casas e os tipos de materiais para fazer os artefatos, bem como o aconselhamento que vem como ensinamento de como se comportar em diversos espaços, para entrar e sair, para participar de determinadas decisões e ações, para se preparar para o futuro, para resolver problemas e dificuldades. Mas isso é transmitido no decorrer das fases da vida.

O entendimento tradicional do Kaiowá sobre o crescimento humano tem sua própria trajetória na linha cultural, constituído, do início ao fim, como: preparação, gestação, nascimento, amamentação, socialização, fase da adolescência, jovem, adulto, casamento e ancião-ñamõi.

Essa linha de crescimento do ser humano é constituída de várias estruturas compostas de regras, que formam camadas, as quais determinam as fases. Isso é o que configura o ñande reko, a própria maneira de viver como Kaiowá, complementada pelo entendimento das manifestações da natureza, das árvores, da chuva, dos animais e dos sonhos, cujos significados interferem nas atividades do cotidiano do Kaiowá.

O contexto social atual é resultado de uma trajetória de desordens ocorrida após a criação da reserva, quando as famílias grandes se espalharam e iniciou-se a desorganização do processo de vivência e autoridade familiar. Mesmo que a reserva estivesse destinada aos indígenas, estes eram explorados, em seu espaço, pela Cia Matte Laranjeira.

Para Brand et al. (2003, p. 4):

[...] líderes dos diversos agrupamentos Kaiowá e guarani que tinham ervais nativos em seus territórios, não aceitavam, pacificamente, a entrada da Cia Matte Laranjeira. Era necessário um amplo e por vezes demorado trabalho de convencimento para que esses aceitassem o corte da erva-mate nos arredores de suas aldeias. [...] cacique não deixava pessoal entrar ali, na erva. Não deixa cortar. Cuidava, antigamente [...]. Então precisa procurar jeito como é que vai entrar.

Buscando entender e descrever esse universo é que a metodologia utilizada para produção e análise dos dados da pesquisa foi a partir da etnografia com 
foco na etnografia pós-moderna, em que "[...] o sujeito deixa de ser pensado como uma entidade prévia ao discurso, para ser tratado como o próprio efeito da discursividade ou da atividade interpretativa" (KLEIN; DAMICO, 2012, p. 67).

Aconteceu através de "visitas" aos mais velhos, com "conversas" intencionalmente sem uma sequência de perguntas predeterminadas, com uma conversa inicial sobre determinado problema ou necessidade, quando os entrevistados foram colocando sua opinião sobre sua vida e conhecimentos.

Paraíso (2012, p. 24 ) coloca que a metodologia também é construída a partir de problemas e questionamentos que vão sendo elaborados ao longo da investigação, na busca de produzir os dados.

Dedicamos esforços para construirmos as nossas metodologias, então, porque sabemos que o modo como fazemos nossas pesquisas vai depender dos questionamentos que fazemos, das interrogações que nos movem e dos problemas que formulamos.

Com isso, foi possível descrever o mundo vasto que existe na cosmovisão do povo Kaiowá, composta de valores, elementos culturais, processos próprios de ensino e aprendizagem, bem como a inserção das crianças Kaiowá para manutenção, ressignificação e fortalecimento de sua identidade.

\section{KUNUMI HÁ CHAMIRI: CRIANÇA KAIOWÁ}

\subsection{A conceituação de criança}

Falar da criança é falar de todas as fases pelas quais as crianças já passaram e que passarão para se tornar bons Kaiowá, cheios de atividades através das quais as crianças se aproximam e transitam no meio dos adultos, constantemente. Toda atividade do adulto também é voltada para o crescimento das crianças. A formação das crianças é feita com inúmeras agendas da comunidade, como cantos, rezas, danças, caças, construção de artefatos e de materiais de caça, de armadilhas, preparação de festas, construção e limpeza das roças. As crianças são sempre envolvidas e presentes, ao lado dos pais, porque é exigência dos pais que a criança fique do seu lado.

Este é o nome dado para a criança: kyrỹi. A partícula ky significa algo verde, que ainda não está maduro ou sólido; kyry - cartilagem do corpo ainda mole; i pequeno, inocente. A enorme abrangência de tudo o que está associado à criança 
ou ao seu entorno forma o seu cenário cultural muito bem definido, com todos os elementos culturais, a partir da sua liberdade de transitar, do respeito por si mesmo e pelas regras postas para serem seguidas para ser um bom Guarani ou Kaiowá.

Essa palavra é sempre seguida de okakuaa-em crescimento. A palavra oka - pátio da casa - tem a ver com o crescimento do pátio que, a partir do cuidado que se tem sobre ele, fica cada vez maior e bonito, demonstrando uma moradia sólida e de respeito. A palavra kuaa significa aprender a ser sábio: continuamente vai criando e aperfeiçoando a mente, o corpo e o entendimento para ser um bom $\mathrm{Pa}^{\prime} \mathrm{i}$ do povo; conhece e respeita os diversos elementos pressupostos da cultura material e imaterial. Kuaa tem a ver com a sabedoria e, neste caso, o batismo é um dos elementos para que seja alcançada, quando a criança recebe o seu verdadeiro nome - itupã réra, nome próprio pelo qual será reconhecida, protegida e respeitada, no meio do povo Tavyterã, assim como por diversos jára, que se manifestam a todo momento.

Se a criança não passar pelo batismo, a família abre mão ou quebra o protocolo cultural, sabendo que seu filho não vai alcançar a perfeição para ser um bom Kaiowá, expondo-o ao risco de ser levado pela manifestação do mau espírito - Jaiguy Jára (conhecido também como Mba'e Tirõ. São seres invisíveis que só os caciques podem ver, são maus espíritos que ficam no bosque, em lugares ruins e fechados e que gostam de prejudicar as pessoas. Eles gostam de criança e da mulher que tem filho recém-nascido, pois não têm a proteção contra ele. Também conhecido por mba'e tirõ, este espírito do mal é um ser que tem corpo transparente, que desce do mundo desconhecido, em determinado período do ano, vive no meio da gente, mas não é visto por qualquer pessoa, só podendo ser visto pelo omba'e kuaáva-aquele que sabe, que tem o controle sobre esses seres, pode vê-los e ouvi-los, contra os quais pode intervir por meio de rezas e cantos.

Também tem o omba'e kuaáva, o/a sábio/a que aprendeu ou adquiriu o dom de cuidar só das crianças, aprendendo a reza, o canto e o remédio somente para usar com as crianças, como se fosse pediatra. As rezas e os cantos - que são os ñe'ẽngáara - são muito diferentes em suas palavras, são os caminho de reza que cada sábio/a vai aprimorando e potencializando e cada um aprende de uma maneira diferente.

O Mba'e Tirõ - mau espírito - gosta muito das crianças, dos recém-nascidos e das meninas com a primeira menstruação. Eles correm o risco de ser levados 
por ele. A forma de levá-los é matando a criança e deixando as meninas muito doentes, podendo, inclusive, enlouquecer. Os Mba'e Tirõ descem do céu uma vez por ano para se alimentar de lixo e de outras coisas ruins que têm na mata e nos lugares por onde o ser humano não transita. Quando descem do céu, trazem muitas doenças, como catapora, feridas que saem na pele de qualquer pessoa, seja adulto ou criança. Por isso tem uma época do ano, depois de florescer a planta jukeri, que serve como calendário - jukeri poty ára rire, em que os rezadores devem cantar e dançar para proteger todos os humanos, benzendo o tempo e espantando a manifestação desse mau espírito.

As crianças também devem tomar banho com remédios tradicionais para crescerem saudáveis, sem a manifestação de doenças. As plantas protegem as crianças para crescer bem e sem adquirir comportamento ruim ou agressivo. Assim também são os cantos e rezas para protegê-las da manifestação do mau espírito.

Em termos de alimentos, as regras também são bem criteriosas. Alguns animais a criança, a mãe e o pai não podem comer e nem mesmo tocar, para não criar anormalidades no crescimento da criança. Isso varia conforme o gênero também: há alimentos que a menina pode comer e há alimentos que só o menino pode comer, assim como partes dos animais. O menino não pode comer a cabeça de uma ave. Se essa parte for consumida pelo menino, com certeza, ao crescer, ele vai adquirir um comportamento de indolência, moleza, não terá força para carregar peso e cansará rápido quando trabalhar. Também não pode consumir o coração de qualquer animal. Ao crescer, ele provoca briga entre os irmãos, pois o comportamento dos animais é assim: agressivos com os irmãos.

A menina não pode correr nem subir nas árvores, nem brincar com os meninos, porque isso provoca a chegada precoce da primeira menstruação. Hoje os mais velhos questionam a escola com relação à quebra das regras culturais, principalmente na Educação Física, que obriga as meninas a fazerem atividades proibidas, como jogar bola. Isso faz com que as meninas corram e brincam com os meninos, prejudicando seu desenvolvimento adequado, segundo as normas culturais. Também é questionado o estudo do corpo humano, na área de Ciências, antes da hora certa.

O pai não pode trabalhar quando a criança ainda é recém-nascida, porque, ao trabalhar, provoca dores no corpo da criança, principalmente quando ele usa ferramentas como enxada, faca e facão, pois isso provoca o sangramento e o crescimento do umbigo na criança. 


\subsection{O sentido da sustentabilidade e a participação das crianças}

A criança-Kunumi e Chamiri-participa de diferentes atividades rotineiras, tanto na família como na comunidade. As brincadeiras preferidas das crianças são canto e reza, que chamam de oñevanga - alegria das crianças, conduzidas por um yvyra'ija - aprendiz de rezador, se for menino; se for menina, é com o acompanhamento da ñande sy, a rezadora.

A sustentabilidade se aproxima do entendimento do Kaiowá. Do ponto de vista indígena é preciso ser pensada por meio do ojeporekái - fazer com as próprias mãos, ser refletida a partir do funcionamento das engrenagens culturais que já existem. Ideologicamente já consolidada a partir de grandes valores da cultura e da diversidade do povo, nessas engrenagens estão construídas as normas, a ética e os elementos culturais a serem seguidos pelo povo Kaiowá que, na língua, se diz ñande reko tee katu, o nosso jeito de ser verdadeiramente.

Essa definição também forma os pilares da educação Kaiowá. Esses pilares definem a maneira como o Kaiowá trata a natureza, como se apropria dela, conhece o território de certos animais, onde vivem as capivaras, em que época podem ser caçadas, onde dá mais peixe para pescar, em que época é proibido transitar no ambiente, conforme o território e o tempo, quem são as pessoas que podem caçar e pescar e quem não pode pescar ou caçar. As crianças participam da construção e da manutenção da sustentabilidade constantemente, como sujeitos que estão aprendendo, mas também fazem a engrenagem funcionar.

Algumas atividades são específicas para o menino. O Kunumi ojovia é o jovem de recado e viajante que leva recado para outra comunidade, como anúncio de festa, casamento, batismo de criança e de milho; também anuncia a pessoa que os deixou - kañyguegui, aquele que morreu. A construção de inúmeras armadilhas fica sob a responsabilidade do menino, para aprender a usar e experimentar em diversos espaços do território. Essa era a maneira de se ocupar para ajudar o pai, como fazer o monde - armadilhas de caça.

A seguir, são explicitados os tipos de construção de monde. Cada monde tem um nome conforme as diferentes formas de armação para pegar diferentes tipos de animais, tais como:

Monde: É a armadilha comum, feita para pegar qualquer animal pequeno ou grande. Sua armação é confeccionada assim: amarra-se um cipó na ponta de 
um pedaço de madeira mais grossa, de um lado só; embaixo, coloca-se um pouco de milho ou de mandioca, deixando-a pronta para que, quando o animal passar por baixo, possa desarmar e cair a madeira pesada em cima do animal.

Monde arata: É feita de madeira pesada e erguida com cipó nas duas pontas; sua armação é para os animais maiores, como tatu, cutia, capivara. Quando desarma, cai em cima do animal, que não consegue se mover por causa do peso da madeira.

Monde pi: É utilizada para pegar pássaros e animais pequenos. É feito um círculo com cipó, onde se coloca o popota, fruta, semente ou algo para atrair os animais. Logo que entra para se alimentar nesse círculo, desarma a armadilha e o cipó bate no animal, tão forte e tão rápido, que não pode mais voar ou andar, fica no círculo da armadilha.

Monde akã jovai: É a armadilha colocada na passagem constante de tatu, capivara e de outros animais que andam sempre pela mesma trilha deixando seu rastro, ou seja, no caminho dos animais que vivem naquele lugar. Monta-se a armadilha na passagem do animal, que, sem perceber, derruba a madeira e, com seu peso, fica preso.

Ñuhãmbe: É uma armadilha que não tem laço, para pegar a pata de animais pequenos, como pássaros, coelhos e outros. Ao desarmar, bate no animal com uma vara, machucando-o.

Ñuhã ñembei: É uma armadilha feita de laço na ponta de uma vara para segurar pela pata. O objetivo é capturar animais pequenos ou grandes, dependendo do tamanho da armação. Pode pegar animais e machucá-los; os grandes ele não mata.

Há também outros artefatos feitos pelos homens e que os meninos devem aprender:

Mimby: Este instrumento é feito de madeira de cedro, e pode ser tocado para anunciar os jára presentes no ambiente. É tocado na hora da tempestade, na dança da chuva, na dança da retomada, na hora do batismo, ao entrar na mata.

Apyka: Este instrumento também é feito de cedro, e é confeccionado para a cerimônia do furo do lábio. Nele, o menino kunumi vai se sentar no dia do Kunumi Pepy.

Guyrapa: É o arco feito para caçar com flecha. São de diferentes tipos, do maior para o menor, conforme cada tipo de caça. 
Guyrapape: É um arco feito para atirar uma bola de barro endurecido ao fogo, como um bodoque. Este é mais para usar com pássaro. Cada um destes instrumentos leva tempo para aprender.

Guyrapa'i: Não são todos que aprendem a fazer este instrumento e também nem todos são ensinados a usá-lo, porque pode provocar inúmeros desentendimentos na vida social da comunidade. Trata-se de um pequeno arco que toca música, mas que só pode ser tocado por pessoa que sabe e, no meio da festa, para atrair mulheres com suas músicas. Ele é proibido de ser aprendido e tocado, porque atrai todas as mulheres casadas, solteiras, novas e velhas.

Óga: A construção da casa também é uma atividade do menino. Sua participação vai desde a montagem até a colocação do sapé, que ele passa para o pai, ou mesmo aprende a colocar o capim na casa. Ele é otecha kuaa - aquele que sabe tecer o sapé, para que a chuva não ultrapasse o teto da casa depois.

Mbaraka: É um instrumento feito de cabaça, para tocar com cantos e rezas. A cabaça deve ser cozida, para ser enfeitada e emitir um som perfeito.

Jepe'a mboaty: Também é tarefa dos meninos ajuntar lenha, sabendo escolher os melhores pedaços, para que o fogo não apague durante dias e noites.

As meninas - Chamiri - também têm inúmeras atividades que deverão ser seguidas no cotidiano.

Takuapurã: É delas o encargo de preparar o takua, instrumento feito de pedaço de bambu, que só as mulheres tocam no momento de reza e canto.

Jeguaka: O cocar também é feito por mulheres. Elas que fazem os melhores enfeites e melhores modelos para cada pessoa. Os homens também fazem, mas preferem aqueles feitos por mulheres.

Po'y miri: O colar também é feito por mulheres. É uma veste sagrada que deve ser usada em todo momento, em diversos espaços, e são as meninas que fazem.

Jehasaha: É uma roupa que se coloca como cinto, mas com enfeites próprios para as cerimônias e também é feita pelas mulheres.

Poatu kambi: É a pulseira que vem com enfeite, para usar também nas cerimônias de casamento e outras festas.

A aprendizagem da preparação dos alimentos é obrigação das meninas:

Jety mbichy: Saber assar as batatas.

Avati mbichy: Saber assar milho-verde. 
Chipa tanimbuguy: Assar um bolo feito de milho embaixo da cinza.

Chipa guasu: Outro tipo de bolo feito de milho-verde, assado no buraco com cinza e carvão colocados em cima da tampa da panela.

Chipa jety irũ: É um bolo feito de milho-verde, mas de forma normal, apenas controlando o aquecimento do fogo.

Chipa tumbykua: É feito de milho-verde, colocado para ferver, e também se põe cinza e carvão em cima da tampa da panela.

Ajaka'i: A construção do cesto feito de cipó é atividade das meninas, assim também a construção do yrupẽ, um grande cesto, feito de taquapi, um tipo de vara específica para isso; nele podem ser carregadas várias coisas dentro.

As meninas fazem visita nas casas dos parentes, mas só quando a mãe vai junto. É proibido às meninas andarem sozinhas sem ser acompanhadas pelos pais. Assim, também, os meninos não podem andar à toa por aí, porque, se o fizerem, eles vão crescendo sem aprender nada. Também é proibido aos meninos comerem carne de vaca e cateto, que são animais agressivos e podem transmitir essa agressividade a eles.

Assim, também, as meninas não podem consumir quaisquer alimentos que podem provocar a chegada da menstruação muito cedo; outros alimentos podem provocar defeito ou anormalidade no seu filho, futuramente. É preciso tomar muito cuidado com seu comportamento; as crianças com deficiência, por exemplo, são consideradas resultado da mãe que zombou de alguma criança deficiente e, por isso, recebe o filho daquele jeito para que possa entender e aprender a viver com essa situação.

Todas as crianças são batizadas e levadas para serem apresentadas ao $P a^{\prime} i$ Kuara para receber a benção de ser sempre uma pessoa limpa, para que fique protegida de inúmeras doenças desconhecidas. É o que se chama de hete potiter o corpo limpo.

O menino não pode comer qualquer alimento. Só é permitido comer peixe, batata assada, chicha e carne de animais como capivara, coelho, veado, tatu, mas sem sal. Aliás, sempre foi proibido o uso de sal nos alimentos, tanto para a menina como para o menino.

O modo de viver das crianças não está distante do modo de viver da comunidade; ela transita junto, aprende junto, experimenta, erra e acerta, com o apoio dos pais e dos mais velhos. O povo Guarani e Kaiowá não visualiza suas crianças 
distantes da realidade, ou seja, não cria espaços só para as crianças, porque os espaços das crianças são os espaços dos adultos. Os pais estão sempre com o kunumi e a chamiri. A liberdade total só é adquirida depois de terem um/a filho/a - petei ojepykypy. Então, ele/ela é deixado pela pessoa que cuidava do casal desde o namoro, casamento, até ter o primeiro filho.

A sustentabilidade é total para o povo Guarani e Kaiowá. Ela ocorre em tudo onde tem vida, não apenas nos valores materiais. A sustentabilidade, como é compreendida pela sociedade capitalista ocidental, distingue-se totalmente da concepção Guarani.

Para Flores (2015, p. 55):

Indígenas não são preservacionistas da natureza, vivem dela, fazem o manejo sustentável, alteram o meio ambiente, no entanto, o que há diferente é que toda essa interferência por ações feitas na natureza visa sempre à preservação da vida de todas as espécies e das condições de sobrevivência dos ecossistemas, no entendimento de que dele depende a vida da atual e das futuras gerações.

Ojeporekái está relacionado à vida e à participação direta das crianças indígenas para o funcionamento das engrenagens culturais. Refere-se ao entendimento total da vida, algo que possui uma dimensão infinita, através do qual é compreendido que o ser humano faz parte desse círculo de energia. Por isso é necessária a busca contínua do funcionamento dessa estabilização cosmológica, da qual faz parte o ser humano, o mundo material e imaterial, que se entrelaçam para manter o mundo cósmico, onde tem os jára, criadores de inúmeros ambientes, fenômenos e espíritos.

A noção do jeporekái é saber o que pode ou não pode caçar e pescar, colher para consumir, ou seja, a procura de alimentos com as regras de respeito aos jára.

A sustentabilidade para o Kaiowá não é pensada ou projetada, mas vivida por meio da manutenção e proteção dos elementos culturais já pressupostos, a fim de continuar estabelecendo as crenças na relação com o mundo e fora dele, considerando-se parte da engrenagem que move a totalidade do mundo.

Os Guarani e Kaiowá sabem que os Mbaíiry - os brancos - não são pessoas estranhas. De acordo com a mitologia Kaiowá, eles também conviveram com os Ñane Ramõi, nosso ancestral, mas têm sua diferença no próprio modo de ser, nas crenças; também forjam o seu sistema cultural, desenham no papel para lembrar 
e relembrar aquilo que fizeram e aquilo que vão fazer. Dessa forma, continuam a sua construção, na imensidade e intensidade da sua cultura, na maneira como os Mbaíry buscam viver, segundo seu próprio entendimento de mundo e estabelecendo sua relação com isso.

Os Mbaíry têm normas criteriosamente definidas, buscam sempre construir novas ideias e, com isso, atropelam a natureza, constroem material superficial, com valores incompatíveis, para dominar, manipular, desenvolver, controlar, disputar, criando inúmeras outras coisas boas e ruins. Os rezadores falam que os Mbaíry também são guardiões, porque vieram também de verdadeiras sabedorias. Um dos seus modos de viver é saber ler e escrever, para construir projetos, planos e passos individuais. Eles não têm muita preocupação com o resultado no coletivo, experimentam suas ideias e só querem avançar. Têm, a priori, o modelo econômico muito ligado à riqueza - com poder de decisão sobre o outro e a natureza, que chamam de sustentabilidade -, segundo o qual a natureza só tem sentido se tiver valor lucrativo.

Muitas coisas que os Mbaíry fazem são boas para eles individualmente, excelentes demais, mas, para o povo indígena Kaiowá, isso precisa ser analisado, pois uma das consequências deste modelo é transformar nossa decisão coletiva em decisões individuais.

Os Mbaíry continuam construindo e indo atrás de respostas para o mundo; com isso, cientificam a natureza, classificando e dando nomes para as coisas que descobrem. Inacia Recarte, rezadora da Aldeia Taquaperi, em depoimento de 2015, assim fala a esse respeito: "Mbaíry kuéra ko heko joguy. Heta ko ha'ekuéra heko ha ndaijapýi, opa mba'e ojapo kuaaa" ("A cultura do branco é imensa e indefinida e, a todo momento, pode mudar e ser recriada, sabe construir muitas coisas").

É perceptível, nessa observação de Inacia Recarte, que os Karai continuam construindo e modificando inúmeras coisas materiais para continuar vivendo e dar sentido à vida, mas essa construção é muito baseada na disputa, no descontrole do outro.

Neste sentido, Azanha (2005, p. 14) afirma: "Nós ocidentais pensamos projetivamente, para as nossas ações [...] fixamos uma meta, pensamos no adiante, produzimos uma idéia para ser alcançada, traçamos um plano, um projeto, fazemos uma projeção em suma". 
Por outro lado, em relação à natureza, o Kaiowá tem outra percepção, outro saber, verdadeiro, e a relação que estabelece com a natureza e o funcionamento dela é para sustentá-la, manter a concepção dos ancestrais - ñanerembypy mba'e, realizando o funcionamento circular, em que a natureza participa junto. O contexto tradicional e atual ainda são processos que mantêm o movimento dessa rede.

Pensamos no futuro, mas não de modo individual, e sim a partir de valores, critérios e normas definidos coletivamente. O próprio indivíduo e as normas mantêm isso, alimentando a rede e assegurando o equilíbrio de trocas com o mundo natural e sobrenatural, onde se compartilha, homens, járas e outros seres, dos recursos naturais; não há necessidade de projetar além do que já é construído e transmitido, para a manutenção de geração para geração e para manter o equilíbrio com o mundo. É neste sentido que o texto busca trazer os elementos culturais e clarear os sentidos, as definições do sistema de funcionamento da engrenagem cultural tradicional, encontrado como cultura autônoma baseada na crença Guarani, que considero hoje parte da sustentabilidade que o Ñane Ramõi Guasu deixou, para que servisse de parâmetro para o povo Tavyterã.

É necessária a compreensão sobre as mudanças nesse novo tempo de viver, de mudanças significativas e insignificativas, principalmente no cenário da cultura tradicional, da pedagogia indígena, das condições sociais, da forma de racionalidade, dos espaços geográficos, da participação direta nas decisões políticas internas e externas, na sustentabilidade e, até mesmo, no modo de ensinar e de aprender das crianças. Não podemos só pensar na cultura tradicional, mas também saber transitar em outras culturas que estão presentes no nosso cotidiano, para compreender, de fato, a constituição dos novos segmentos e veículos de informações que permeiam a comunidade. Para isso, a escola é o espaço adequado para confrontar, criar e recriar a epistemologia que dê conta da realidade.

Assim, como diz Paraíso (2012, p. 26):

Mudaram a estratégia de "colonizar", de educar e de governar. Mudaram os pensamentos, os raciocínios, os modos de "descolonizar", os mapas culturais. Nesses novos Mapas políticos e culturais [...], mudaram as formas como vemos, ouvimos, sentimos, fazemos e dizemos o mundo. Mudaram a nossas perguntas e as coisas do mundo. Mudaram os "outros" e mudamos nós.

Com isso a escola, então, transforma-se num território de defesa, de retomada de consciência sobre os valores culturais e interculturais, num espaço de 
estranhamentos e de compreensão. O espaço da escola influencia na construção da identidade.

Na percepção de Hall (1997, p. 26), a nossa identidade é construída também a partir das representações e dos significados que se apresentam para nós:

A identidade emerge, não tanto de um centro interior, de um "eu verdadeiro e único", mas do diálogo entre os conceitos e definições que são representados para nós pelo discurso de uma cultura e pelo nosso desejo (consciente ou inconsciente) de responder aos apelos feitos por estes significados, de sermos interpelados por eles, de assumirmos as posições de sujeito construídas para nós.

Assim, o cenário do contexto atual e as identidades constituídas nas gerações são resultados de mudanças que já ocorreram e ainda ocorrem constantemente, a partir das informações, materialização dos valores, das resistências e potencialização dos conhecimentos indígenas por meio do saber externo. Devemos ter a consciência de que essa identidade atual teve a sua trajetória de resistências e negociações e resultou no saber que se visualiza como não tradicional, mas também não totalmente externo. É um saber que está preparado para dialogar com dois conhecimentos.

Outra grande desvantagem para o fortalecimento da identidade dos Kaiowá é a instalação de igrejas na comunidade. O espaço da igreja, hoje, é espaço de transformação e não aceita novas ideias e, muito menos, o fortalecimento da identidade e das crenças indígenas. A continuidade da imposição da igreja ainda é imensa, a diferença é que, agora, é feita pelo próprio indígena e com uma grande quantidade de indígenas pastores despreparados, que trazem mais problemas na comunidade do que organização e que não se preocupam em ajudar a comunidade a superar os diversos problemas sociais.

Essa trajetória de negação da identidade foi notável, assim como aconteceu com Benites, (2014, p. 19).

Quanto mais me envolvia com a sociedade não indígena, através da escola e da igreja, nascia, no meu interior, a necessidade de me adaptar a ela, a partir da negação da minha identidade, da língua materna e, principalmente, negar o lugar onde moro. Via que todos os elementos da minha cultura eram como coisas negativas, ruins, uma deformação.

Isso cria um espaço conflituoso, porque é composto por ambas as concepções: a compreensão do próprio povo e, também, a constante imposição da 
instituição eclesial, que formula novas lógicas e políticas, na busca de se apropriar da decisão completa.

A sustentabilidade precisa ser retomada, não só no sentido alimentar, mas como teko, como modo de ser do povo, agora potencializada com novos saberes e com as melhores ideias e entendimento externo, sem deixar de ser coletiva, sem deixar de cantar, de rezar e de respeitar a natureza. Agora, a nova sustentabilidade precisa se apropriar dos conhecimentos que podem ser utilizados para a nova organização social atual e para o controle da vida social atual, como os da escola. Esta é uma ferramenta privilegiada para a formação de novas identidades que compreendem o campo da sociedade envolvente e o campo dos saberes tradicionais.

Assim, o espaço escolar precisa se preparar pedagogicamente para receber as crianças Kaiowá, para que estas possam se aventurar nos dois ou mais conhecimentos (não só ocidentais), tendo em vista entender que o mundo em que vivemos atualmente é composto de diversidades e que não estamos mais sós. Por isso os professores indígenas terão de se formar como guardiões dos dois conhecimentos (tradicional e da sociedade majoritária) e saber usá-los no espaço da escola.

As pessoas que operacionalizam o sistema precisam entender a legislação da educação escolar indígena, para saber inserir a escola diferenciada no sistema. Infelizmente, pela falta de conhecimentos destes profissionais, que não se esforçam em buscar mecanismos para inseri-la no sistema, ou criar a flexibilidade para executar a educação escolar indígena da maneira como está garantida na legislação, a escola indígena é obrigada a participar de inúmeras avaliações que não dizem respeito à sua realidade pedagógica. Isso se torna um obstáculo para a efetivação da educação escolar indígena e para sua continuidade. É necessária uma atenção constante para garantir a diferença, conforme a legislação.

A Resolução 05/2012, que define Diretrizes Curriculares Nacionais para a Educação Escolar Indígena na Educação Básica (BRASIL, 2012, p. 3), diz o seguinte:

Art. 60 Os sistemas de ensino devem assegurar às escolas indígenas estrutura adequada às necessidades dos estudantes e das especificidades pedagógicas da educação diferenciada, garantindo laboratórios, bibliotecas, espaços para atividades esportivas e artístico-culturais, assim como equipamentos que garantam a oferta de uma educação escolar de qualidade sociocultural. 
A postura da escola indígena ainda é questionada pelos mais velhos, pela divulgação que faz por meio de professores de se posicionar como inovadora da educação para a comunidade, sem consultar os mais velhos e sem saber o que de fato a comunidade quer que seja trabalhado na educação escolar. Ser professor é ocupar um espaço muito importante na comunidade, mas, para que seja eficiente, é necessária a formação específica e contínua, para entender e saber conviver no contexto atual, valorizando e respeitando os mais velhos e, também, para poder visualizar um novo caminho de educação para as novas gerações por meio da escola.

Infelizmente, após décadas da criação da escola indígena, legalmente, em muitas comunidades não mudou muito o paradigma escolar, mesmo que, agora, a escola nas aldeias seja composta, em parte, por professores indígenas. O modelo de ensino e aprendizagem ainda continua sendo definido pelos técnicos da Secretaria de Educação do Município e do Estado, chega com formato pronto, fragmentado em sua pedagogia, fechado, controlado e imposto. Muitas vezes, os professores indígenas são obrigados a seguir esse modelo padronizado.

A escola indígena Ñande Reko Arandu, da aldeia Taquaperi, ainda busca acertar na pedagogia que se aproxima da educação Kaiowá. Mas há um desafio que a escola precisa superar, por meio da sua direção e do corpo de professores: envolver, de fato, a comunidade na construção da escola. Os mais velhos têm razão de questionar por que não são ouvidos, quando a escola se posiciona como a que sabe tudo, mas não dá conta da educação que eles chamam de "verdadeira"; eles não acreditam que os livros vão trazer os elementos para serem melhores pessoas, sendo que a vivência, a cultura e os pilares educativos do povo Kaiowá são para isso.

É preciso garantir a compreensão dos direitos e deveres assegurados na legislação enquanto prioridades no âmbito da escola indígena, como o que está previsto na Constituição Federal (BRASIL, 1988).

Art. 231. São reconhecidos aos índios sua organização social, costumes, línguas, crenças e tradições, e os direitos originários sobre a terra que tradicionalmente ocupam, competindo à união demarcá-las, proteger e fazer respeitar todos os seus bens.

Atualmente, a escola se tornou parte das fases da criança Kaiowá, ou mesmo, a maior parte da sua vida. Este instrumento sempre foi considerado como 
Mbaíry Reko - não indígena, de fora. Mas hoje se busca, por meio de trabalhos, pesquisas e experimentos dos professores, dar novos sentidos para a escola, como instrumento interno.

É preciso que a escola transforme, de fato, o seu ambiente em espaço de interculturalidade, questionador da identidade Kaiowá, mas também para trazer novos elementos fortalecedores da diferença, pensando e analisando sempre que o contexto estiver atrelado a outros saberes e alterado por eles.

Batalla (1998, p. 8) analisa muito bem este aspecto:

Cultura apropiada. Este ámbito se forma cuando el grupo adquiere la capacidad de decisión sobre elementos culturales ajenos y los usa en acciones que responden a decisiones propias. Los elementos continúan siendo ajenos en tanto el grupo no adquiere también la capacidad de producirlos o reproducirlos por sí mismo; por lo tanto, hay dependencia en cuanto a la disponibilidad do esos elementos culturales, pero no en cuanto a las decisiones sobre su uso.

A escola carece trabalhar com outros conhecimentos, mas deve considerar, num primeiro momento, o entendimento do professor Kaiowá, a transformação que o professor indígena faz do sentido, do entendimento e dos valores de determinados conteúdos escolares. Assim, os conteúdos escolares passam a ser pensados, traduzidos e transmitidos por meio das concepções Kaiowá, e a linguagem é uma das ferramentas para efetivar esse processo.

A diferença é enorme quando o professor faz um plano sobre determinados conteúdos, trazendo o entendimento e o debate do tema para a realidade, mesmo que, operacionalmente, seja trabalhado com o objetivo de tornar os alunos bons leitores e escritores e conhecer o numeramento. Isso significa que os saberes não passam na escola indígena do jeito que ela vem conceituada pelo currículo comum. Mas quem consegue fazer essa transposição/tradução é o professor indígena formado, principalmente o profissional que conhece, tradicionalmente, os saberes indígenas e com o qual a maior parte do fazer pedagógico é realizada de modo indígena.

Outra diferença que ocorre na escola, perceptível hoje em dia, é a importância da oralidade na educação. Os professores indígenas não priorizam muito essa forma de avaliação. Os conhecimentos teóricos, exigidos pela escola, são avaliados somente através de prova escrita, e sempre resultam em notas baixas para os alunos. 
A avaliação de um professor indígena deveria ser centrada no resultado que repercutirá na vida do aluno, em seu contexto social. Esta conduta avaliativa faz a maior diferença no objetivo do professor indígena. Para isso, é necessário trabalhar certos conteúdos selecionados que se aproximam da realidade e, para a avaliação, observa-se a mudança no contexto social. Esse tipo de avaliação não faz parte do modelo pedagógico da escola, mas faz muita diferença para o professor indígena, a comunidade e, principalmente, para o aluno.

A confusão acontece quando um professor não indígena trabalha o conceito de um determinado conteúdo em Língua Portuguesa, e os alunos, por si mesmos, precisam transformá-lo em pensamento Guarani.

As ideias que chegam à escola sempre serão "verdadeiras" para o Kaiowá. Então, é necessário dar novos sentidos para o espaço escolar, em que possamos acreditar e mostrar-nos disponíveis e confiantes para conhecer o que não é conhecido, falar o que não se pode falar, experimentar o que não se pode experimentar, construir o que não se pode entender, começar o que não se pode começar, diferenciar o que é velho e o que é novo, estimular, conhecer e nos prepararmos para nos aventurar pelos caminhos desconhecidos, tal como fizeram nossos pais ancestrais ao saírem pelo mundo à procura de Ñane Ramõi Papa. Ao voltarmos, com opiniões diferentes e comprometidos com nossa comunidade e povo, compreenderemos a disputa, a contrariedade, a traição e repensaremos o que causa a desunião da comunidade, o que leva ao desentendimento e às mudanças e, por fim, encontraremos o círculo aconchegante deixado como herança pelos nossos ancestrais, ou seja, o caminho da união. A escola deve ser um espaço de aventura.

\section{CONSIDERAÇÕES FINAIS}

O entendimento de mundo pelo povo Kaiowá é extenso. No decorrer da pesquisa, foram desvendados inúmeros valores culturais ainda muito presentes na comunidade e muitos se tornaram apenas lembrança para os mais velhos, sem expectativa de retorno.

A pesquisa possibilitou trazer uma perspectiva muito grande como instrução e orientação sobre os processos próprios de ensino e aprendizagem do povo Kaiowá fora da escola. Muitos desses elementos culturais precisam, urgentemente, ser incorporados ao modelo pedagógico da escola indígena, não como processos 
próprios de ensino-aprendizagem desconhecidos, mas como característica dos processos de ensino e aprendizagem escolar e acadêmica.

O espaço escolar deve se transformar, reinventar-se, para trazer novamente a esperança para a comunidade e, principalmente, para os mais velhos, que se silenciam ao ver a vida atual dos jovens, das mulheres, dos homens, que caminham de forma confusa por não saber ou não querer praticar a educação Kaiowá.

O caminhar da escola indígena precisa estar concentrado na diversidade, nas diferenças e na interculturalidade como mecanismos de resistência. Vejo a escola como instrumento importantíssimo para a comunidade, mas ela precisa integrar, aos poucos, todos os critérios já estabelecidos para ser escola indígena. Também, aos poucos, a escola e sua gestão precisam inserir professores indígenas com experiência técnica para acompanhá-la no sistema.

\section{REFERÊNCIAS}

AZANHA, Gilberto. Sustentabilidade nas sociedades indígenas brasileiras. Revista Tellus, Campo Grande, MS, ano 5, n. 8/9, p. 11-28, abr./out. 2005.

BATALLA, Guillermo Bonfil. La teoría del control cultural en el estudio de procesos étnicos. Brasília: Universidade de Brasília, 1988.

BENITES, Eliel. Oguata Pyahu (Uma nova caminhada) no processo de desconstrução e construção da Educação Escolar Indígena da Aldeia Te'ýikue. 2014. 130f. Dissertação (Mestrado em Educação)- Universidade Católica Dom Bosco, Campo Grande, MS, 2014.

BRAND, Antônio; FERREIRA, Eva Maria L.; TSCKINKEL JÚNIOR, Rene; BATISTA, Suzana G. Os Kaiowá e Guarani em tempos da Cia Matte Larangeira. In: SIMPÓSIO NACIONAL DE HISTÓRIA (ANPUH), 22., 2003, João Pessoa, PB. Anais [...]. João Pessoa, PB: ANPUH, 2003.

BRASIL. Ministério da Saúde. Secretaria Especial de Saúde Indígena (SESAI). Relatório Saúde Indígena etnia Kaiowá, MS. Brasília, DF, 2016.

BRASIL. Ministério da Educação. Conselho Nacional de Educação. Resolução 05/2012. Brasília, 2012.

BRASIL. Congresso Nacional. Constituição da República Federativa do Brasil. Brasília, DF: Presidência da República, 1988. 
FLORES, Lucio Paiva. O lugar onde as pedras falam. In: MARKUS Cledes; ALTMANN, Lori; GIERUS, Renate (Org.). Saberes e espiritualidade indígena. São Leopoldo, RS: Oikos, 2014. HALL, Stuart. A centralidade da cultura: notas sobre a revolução cultural de nosso tempo. Educação e Realidade, Porto Alegre, RS, v. 22, n. 2, p. 15-46, jul./dez. 1997.

KLEIN, Carin; DAMICO, José. O uso da etnografia pós-moderna para a investigação de políticas públicas de inclusão social. In: MEYER, Dagmar Estermann; PARAísO, Marlucy Alves (Org.). Metodologias de pesquisas pós-críticas em educação. Belo Horizonte: Mazza Edições, 2012. p. 63-86.

PARAÍSO, Marlucy Alves. Metodologias de pesquisa pós-criticas em educação e currículo: trajetórias, pressupostos, procedimentos e estratégias analíticas. In: MEYER, Dagmar Estermann; PARAísO, Marlucy Alves (Org.). Metodologias de pesquisas pós-críticas em Educação. Belo Horizonte: Mazza Edições, 2012. v. 1, p. 24-47.

\section{Sobre os autores:}

Claudemiro Pereira Lescano: Doutorando no Programa de Pós-Graduação em História (PPGH) da Universidade Federal da Grande Dourados (UFGD). Mestre pelo Programa de Pós-Graduação em Educação (PPGE) da Universidade Católica Dom Bosco (UCDB). Professor indígena da comunidade da aldeia Taquaperi, município de Coronel Sapucaia, Mato Grosso do Sul. E-mail: guaranilescano@gmail.com, Orcid: http://orcid.org/0000-0003-2879-2233

Heitor Queiroz de Medeiros: Doutor em Ciências pela Universidade Federal de São Carlos (UFSCar). Docente no Programa de Pós-Graduação em Educação (PPGE) da Universidade Católica Dom Bosco (UCDB). Líder do Grupo de Pesquisa Diversidade Cultural, Educação Ambiental e Arte (CNPq). E-mail: heitor.medeiros@ucdb.br, Orcid: http://orcid.org/0000-0001-5313-1811

\section{Recebido em 14 março 2019 Aprovado em 10 de novembro de 2019}


